\title{
Fabrication and Characterization of Polyvinylpyrrolidone-Eggshell Membrane-Reduced Graphene Oxide Nanofibers for Tissue Engineering Applications
}

\author{
Shahnaz Ghorbanzadeh Sheish ${ }^{1}$, Rahmatollah Emadi ${ }^{2}$, Mehdi Ahmadian ${ }^{2}$, Sorour Sadeghzade ${ }^{2,3, *(D)}$ \\ and Fariborz Tavangarian ${ }^{3, *}$ \\ 1 Materials Engineering Group, Pardis College, Isfahan University of Technology, Isfahan 84156-83111, Iran; \\ s.ghorbanzadeh@pa.iut.ac.ir \\ 2 Department of Materials Engineering, Isfahan University of Technology, Isfahan 84156-83111, Iran; \\ remadi@cc.iut.ac.ir (R.E.); ahmadian@cc.iut.ac.ir (M.A.) \\ 3 Mechanical Engineering Program, School of Science, Engineering and Technology, Penn State Harrisburg, \\ Middletown, PA 17057, USA \\ * Correspondence: soroursadeghzade@gmail.com or s.sadeghzadeh@ma.iut.ac.ir (S.S.); \\ f_tavangarian@yahoo.com or fut16@psu.edu (F.T.)
}

check for updates

Citation: Ghorbanzadeh Sheish,

S.; Emadi, R.; Ahmadian, M.;

Sadeghzade, S.; Tavangarian, F.

Fabrication and Characterization of Polyvinylpyrrolidone-Eggshell Membrane-Reduced Graphene Oxide Nanofibers for Tissue Engineering Applications. Polymers 2021, 13, 913. https://doi.org/10.3390/polym13060913

Academic Editor: Juliana Dias

Received: 12 February 2021

Accepted: 10 March 2021

Published: 16 March 2021

Publisher's Note: MDPI stays neutral with regard to jurisdictional claims in published maps and institutional affiliations.

Copyright: (c) 2021 by the authors. Licensee MDPI, Basel, Switzerland. This article is an open access article distributed under the terms and conditions of the Creative Commons Attribution (CC BY) license (https:// creativecommons.org/licenses/by/ $4.0 /)$

\begin{abstract}
One of the best methods to prevent wound infection and speed up wound healing is wound dressing based on nanofiber-polymer scaffolds, which have acceptable antimicrobial performance and appropriate skin regeneration capabilities. In this paper, the electrospinning method was applied to synthesize the polyvinylpyrrolidone-acrylic acid hydrogel (PVPA)-eggshell membrane (ESM)-reduced graphene oxide ( $\mathrm{rGO}$ ) nanosheets nanocomposite dressings with different reduced graphene oxide contents $(0,0.5,1$, and $2 \mathrm{wt} . \%)$. Thus, smooth nanofibers were fabricated, including a high amount of rGO, which reduced the fiber diameter. Based on the results, rGO played an important role in water impermeability. The results showed that by increasing the rGO concentration from 0.5 to $2 \mathrm{wt} \%$, the contact angle value increased persistently. Results showed that compared to PVPA-ESM, the mechanical strength and strain of PVPA-ESM $/ 1 \mathrm{wt} \% \mathrm{rGO}$ significantly enhanced $28 \%$ and $23 \%$, respectively. Incorporation of $1 \mathrm{wt} \%$ rGO enhanced swelling ratio from $875 \%$ for PVPA-ESM to $1235 \%$ after $420 \mathrm{~min}$, while increasing the rGO to $2 \mathrm{wt} \%$ increased the degradation rate of the composites. According to the in vitro cell culture studies, PVPA-ESM wound dressings with $0.5-1 \mathrm{wt} \%$ rGO content enhanced PC12 cell viability compared to the wound dressings without rGO nanosheets. Generally, rGO-loaded PVPA-ESM nanofiber wound dressing can be considered as a potential candidate to be used in skin regeneration applications.
\end{abstract}

Keywords: electrospinning; polyvinylpyrrolidone; eggshell membrane; graphene oxide; biocompatibility; wound dressing

\section{Introduction}

The first protective obstacle to the external environment is human skin, which defends the body against microbial intrusion and ample water loss [1-3]. Patients suffering from burn injuries and those who have had surgeries are vulnerable to systemic immunosuppression and are at a high risk of infection [4,5]. Approximately two-thirds of deaths in these patients are due to the aforementioned conditions [6-8]. Moreover, one of the greatest threats to human health is the infection issuance due to drug-resistant pathogens $[9,10]$. Consequently, researchers are more persuaded to suggest different remedies [11]. One of the low-cost methods to generate fibrous polymers for wound dressing is electro-spinning. By selecting the correct materials in this method, some biological substitutes can be produced for skin defects. By controlling the size and percentages of porosities and creating substantial surface-area-to-volume ratios, this method has prominent features beneficial for the biomedical fields [12-14]. 
Polyvinylpyrrolidone (PVP) has been introduced as a synthetic polymer with high biocompatibility, chemical stability, great film-forming ability, and mechanical properties $[15,16]$. PVP-based hydrogels have an important role in wound dressing application [17]. These macromolecular systems can incorporate an aqueous medium. Wetting capabilities, architecture, and their structure properties can influence the faster healing of skin tissue regeneration [18]. The softness and high-water content of PVP hydrogels resembles natural living tissues more than any other type of synthetic biomaterial, which also contributes to their biodegradability and biocompatibility [19]. However, PVP hydrogels are limited in their usage due to their weak mechanical properties. To increase its mechanical properties, PVP, and its monomer, $N$-vinyl pyrrolidone have been copolymerized with acrylic acid and other vinyl monomers [20,21]. Incorporating the reinforcement agents into the polymer matrix prevents the diffusion of substances through the membrane [22,23]. The performance of these multicomponent systems can be optimized by their synergic features [24]. On the other hand, GO is more appropriate for biomedical applications because of the hydrophilicity that is provided by hydroxyl and carboxyl groups [25,26]. These groups enable GO [27] to be functionalized by a range of synthetic and natural molecules, including proteins, polymers, nanoparticles, and small molecules [28]. The cytotoxicity of GO-functionalized materials can be reduced by protein [29]. To acquire hybrid composites with great material features and electrical conductivity, researchers in previous studies have used polymers with graphene-based nanomaterials, with excellent mechanical and physical properties [30]. Many polymer-GO composite nanofibers have been produced in recent years [31]. Pant et al. [32] made nylon-6 spider-wavelike nano-nets via embedding proper levels of GO in the polymer solution by using electrospinning [33,34]. As a result, the hydrogen bond formation between polymer molecules and the GO sheet leads to the nice dispersing of the GO nanosheet in the nylon-6 solution. PVP-GO nanofibers were fabricated via electrospinning by Liu [35]. Although the electrospinning of synthetic PVP-based nanofiber is complex, it needs a sizeable organic solvency content [36]. Due to the high consumption of hen eggs around the world, a large amount of discarded egg wastes consists of eggshell (ES) and eggshell membrane (ESM) is available [37]. ES and ESM are inorganic and organic materials that have a wide range of applications such as soil conditioner, initial material for the synthesis of bioceramics and collagen, and recently for wound dressing [38]. Among these applications, much interest has been devoted to the use of eggshell powder as reinforcement in polymer industries. Saeb et al. [39] utilized hen eggshell due to the peptide functional groups and proteins in its structure to create a material for curing aid purposes when added to the epoxy resin. In another study, Subramani Bhagavatheswaran et al. [40] mentioned that adding ES (with superior properties and low price) biowaste powder in polymer matrix can develop a biodegradable polymer which can reduce the contaminants in environment. They fabricated a new biodegradable acrylonitrile butadiene rubber (NBR) reinforced with $\mathrm{ES}$ and $\mathrm{CaCO}_{3}$ micro-fillers with improved mechanical properties [40]. Eggshell membrane (ESM) is an inorganic waste material containing more than 500 proteins and peptides, including collagens, glycoproteins, etc. [41]. ESM attract much attention in recent years due to its biological functions such as anti-adhesive, antioxidant properties, anticancer, and antimicrobial [42]. Furthermore, ESM has appropriate properties for medical applications such as suitable moisture retention, air permeability, cell response action of amino acids, and the ability to attach to textured surfaces due to its network structure [43,44]. Researchers [43] have used ESM as a biodegradable bone reproduction inhibitor, a media for biosorption, and a template for forming ordered tube networks [43]. Moreover, recently, ESM powder was used as wound dressing in a mouse excisional which accelerated the wound closure, improved tissue formation, and accelerated the deposition of collagen at the wound location [42]. Blending biopolymers with synthetic polymers to produce new polymeric materials with better properties received great attention [44]. To design the appropriate wound dressing with high biological and mechanical properties, a mixture of ESM, PVP, and GO nanosheets can be a good idea due to the aforementioned properties. The aim of this paper was to 
develop wound dressings composed of PVPA-ESM/rGO nanosheets. PVPA-ESM/rGO nanofibers were fabricated via electrospinning technique. Then, they were tested in vitro to determine their capability in the wound healing process. ESM was selected as the base material for electrospinning in aqueous media. PVP's electrospinning processability was chosen as the supporting polymer for incorporating the ESM. The effects of adding rGO nanosheets into the PVPA-ESM nanofibers composite on the biological, mechanical, and wettability of these nanofibers composite was evaluated.

\section{Materials and Methods}

\subsection{Materials}

Polyvinylpyrrolidone (PVP, $\left.\left(\mathrm{C}_{6} \mathrm{H}_{9} \mathrm{NO}\right)_{\mathrm{n}}, \mathrm{M}_{\mathrm{W}}=40,000 \mathrm{~g} / \mathrm{mol}\right)$ was purchased from Sigma-Aldrich Co., Cleveland, OH, USA. Acrylic acid $\left(\mathrm{CH}_{2}=\mathrm{CHCOOH}, \mathrm{M}_{\mathrm{w}}=72 / 06 \mathrm{~g} / \mathrm{mol}\right)$, and methylene bisacrylamide $\left(\mathrm{C}_{7} \mathrm{H}_{10} \mathrm{~N}_{2} \mathrm{O}_{2}, \mathrm{M}_{\mathrm{W}}=154.17 \mathrm{~g} / \mathrm{mol}\right)$, and potassium persulfate $\left(\mathrm{K}_{2} \mathrm{~S}_{2} \mathrm{O}_{8}, \mathrm{M}_{\mathrm{W}}=270.322 \mathrm{~g} / \mathrm{mol}\right)$ were used as monomer, cross-linking agent, and initiator, respectively, and were purchased from Sigma-Aldrich Co., Cleveland, $\mathrm{OH}$, USA. Triton ${ }^{\mathrm{TM}}$ $\mathrm{X}-100$ was purchased from Sigma-Aldrich Co., Cleveland, OH, USA $\left(\mathrm{C}_{14} \mathrm{H}_{22} \mathrm{O}\left(\mathrm{C}_{2} \mathrm{H}_{4} \mathrm{O}\right)_{\mathrm{n}}\right.$ ( $\mathrm{n}=9-10), \mathrm{M}_{\mathrm{W}}=647 \mathrm{~g} \mathrm{~mol}^{-1}$ ) as surfactant. Graphite powder, $\mathrm{H}_{2} \mathrm{SO}_{4}, \mathrm{H}_{3} \mathrm{PO}_{4}, \mathrm{KMnO}_{4}$, $\mathrm{H}_{2} \mathrm{O}_{2}(30 \%)$, and hydrazine hydrate were purchased from Sigma-Aldrich Co., Cleveland, $\mathrm{OH}$, USA. Glycerol and $\mathrm{CaCl}_{2}$ were attained from Merck Co., Munich Germany. Hen eggs were bought from the local market (Isfahan, Iran). Deionized (DI) was used in all parts of the experiment.

\subsection{Preparation of the Eggshell Membrane (ESM)}

First, the egg white and yolk were removed through a small piercing at the blunt tip of the egg. Then, after washing the eggshell with deionized water and to separate ESM from the shell, it was soaked in $\mathrm{HCl}(1 \mathrm{M})$ solution at $25^{\circ} \mathrm{C}$ for $1 \mathrm{~h}$. In the next step, the ESM was rinsed using deionized water. The extracted ESM was attained after drying in a vacuum oven at $40{ }^{\circ} \mathrm{C}$ for $24 \mathrm{~h}$. Finally, the membranes were cut into small pieces for preparing the electrospinning solution.

\subsection{Fabrication and Crosslinking Procedure of PVP/Acrylic Acid-Based Hydrogel}

Free radical polymerization technique was used to fabricate PVP/acrylic acid-based hydrogel (the obtained material was called PVPA). For this purpose, aqueous solutions of acrylic acid ( $1 \mathrm{wt}$. \%) was prepared and then $5 \mathrm{~g}$ PVP was added to this solution to fabricate $\mathrm{PVP} /$ acrylic acid hydrogel (marked as solution A). The cross-linking agent $\left(\mathrm{C}_{7} \mathrm{H}_{10} \mathrm{~N}_{2} \mathrm{O}_{2}\right)$ and initiator $\left(\mathrm{K}_{2} \mathrm{~S}_{2} \mathrm{O}_{8}\right)$ with concentration of $3 w / w$ were chosen and were added dropwise into solution A and stirred for $1 \mathrm{~h}$. Finally, the prepared hydrogel solution was kept in oven at $25^{\circ} \mathrm{C}$ for $4 \mathrm{~h}$. The hydrogel was then removed and placed in distilled water for $24 \mathrm{~h}$ to remove unreacted monomers (Figure $1 \mathrm{a}$ ).

\subsection{Synthesis of Reduced Graphene Oxide (rGO)}

The GO nanosheets were provided by a modified Hummer's method as described in [45]. Briefly, graphite and $\mathrm{KMnO}_{4}$ (ratio as 1:6 g) were blended with a mixture of $\mathrm{H}_{2} \mathrm{SO}_{4}$ and $\mathrm{H}_{3} \mathrm{PO}_{4}$ acids with a ratio of 180:20 mL and stirred at $50{ }^{\circ} \mathrm{C}$ for $12 \mathrm{~h}$. Then, the solution was cooled down at ambient temperature in water solution containing $30 \% \mathrm{H}_{2} \mathrm{O}_{2}$. In the next step, the suspension was centrifuged, washed, and then was kept in vacuum oven at $60^{\circ} \mathrm{C}$ for $24 \mathrm{~h}$. The chemical reduction method was used to reduced graphene oxide. Hydrazine hydrate was used as a reducing agent, and this mixture was heated at $85^{\circ} \mathrm{C}$ for $24 \mathrm{~h}$. The produced reduced graphene oxide (rGO) was used as additive in PVPA-ESM composite. 
(b)

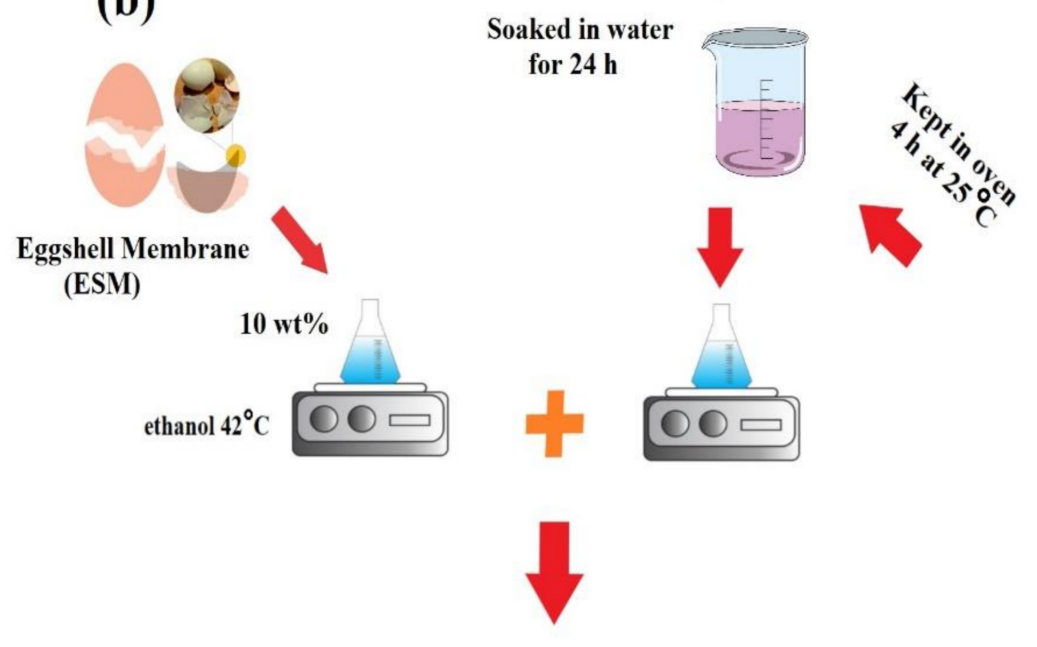

PVPA

$\mathrm{K}_{2} \mathrm{~S}_{2} \mathrm{O}_{8}$

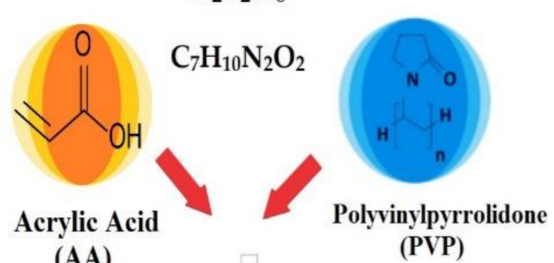

(AA) (a)

(c)

$0,0.5,1,2 w t \%$
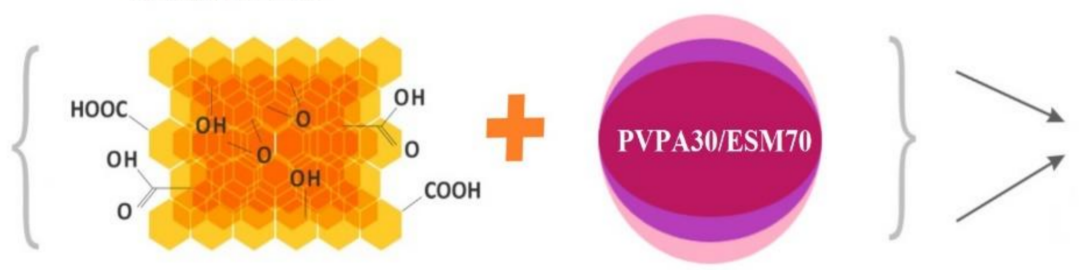

$00 \square$

Reduced Graphene Oxide (rGO)

Electrospinning

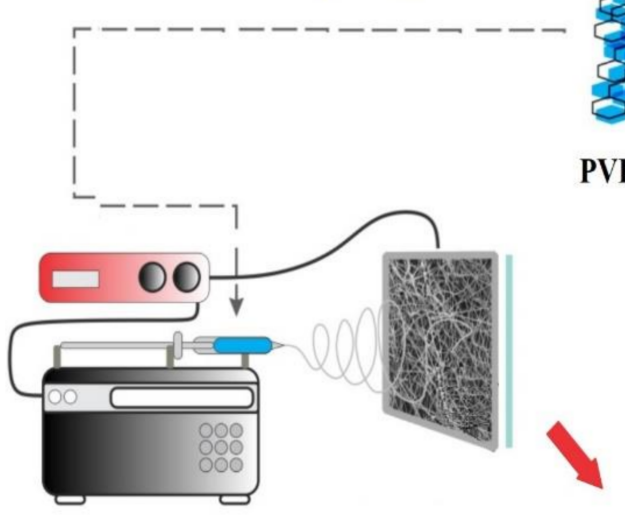

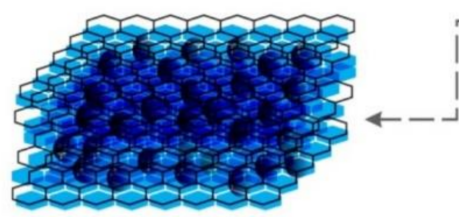

PVPA-ESM-rGO nano sheets
Combination

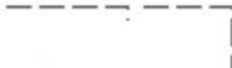

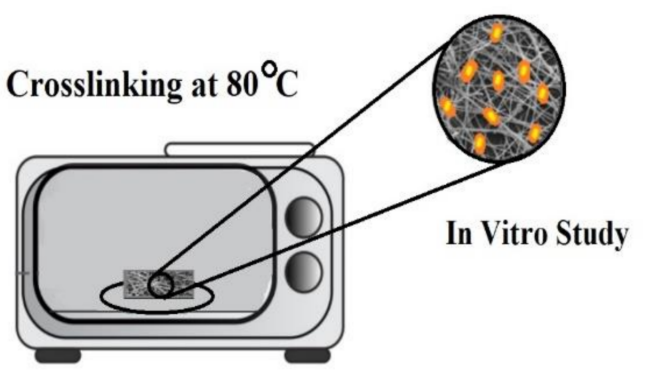

Figure 1. Schematic representation of the fabrication of (a) PVP/acrylic acid-based hydrogel, (b) eggshell membrane solution, and (c) the electrospun PVPA-ESM fibers modified by rGO nanosheets.

\subsection{Fabrication Procedure of PVPA-ESM/rGO Nanofibers}

The electrospinning technique was chosen to synthesize the PVPA-ESM/rGO nanocomposite with various amounts of rGO nanosheets. The ESM solution (10 wt.\% ethanol-based solution, Figure $1 \mathrm{~b}$ ) was then fabricated and added to the PVPA solution with a $v / v$ ratio of 70/30. Then, $0,0.5,1$ and 2 wt.\% of rGO nanosheets were added to this solution to enhance spinnability. Before starting the electrospinning process, to improve the suspensions' spinnability, Triton 100 at the concentration of $0.5 \mathrm{wt} \%$ was added to the suspensions. 
After that, to have a homogenous dispersion of the rGO nanosheets, the prepared solution was sonicated for $30 \mathrm{~min}$ (ES375H BENCH, Hilsonic Ultrasonic Cleaners Co., Cashel Road, Wirral, Merseyside, UK) at an ambient temperature. To fabricate the PVPA-ESM/rGO nanofibers, the prepared suspensions were fed into a $1 \mathrm{~mL}$ syringe having a $23 \mathrm{G}$ blunted stainless-steel needle and were electrospun (Figure 1c). Throughout the electrospinning process, the voltage, flow rate, and the tip to the collector distance were considered as 18 $\mathrm{kV}, 0.12 \mathrm{~mL} / \mathrm{h}$, and $15 \mathrm{~cm}$, respectively. To prepare the electrospinning PVPA-ESM/rGO nanofibers, a grounded aluminum foil was used as a collector. After electrospinning and before crosslinking, the fabricated nanofibers were dried in a vacuum desiccator at room temperature for $24 \mathrm{~h}$. At the end, the nanofibers were kept at $80^{\circ} \mathrm{C}$ overnight and then soaked in methanol for $1 \mathrm{~h}$ to crosslink PVPA for further experiments. A distance of $1 \mathrm{~cm}$ was considered between the cage bars and the collector's rotation speed ( $800 \mathrm{rpm})$. Random nanofibers were deposited on the aluminum foil slide placed on the collector plate.

\subsection{Measurements and Characterizations of PVPA-ESM-rGO Nanofibers}

The sessile drop method and a contact angle goniometer (KRUSS, DSA25, Hamburg, Germany) were used to measure the wettability of samples at the room temperature $\left(25^{\circ} \mathrm{C}\right)$. The sessile drop was formed by depositing $2 \mu \mathrm{L}$ of the test liquid using an automatic micro-syringe. To specify the weight loss of the cross-linked nanofibers, three samples from each model with a weight of about $2 \mathrm{mg}$ were immersed in phosphate-buffered saline (PBS) solution at $37{ }^{\circ} \mathrm{C}$ with $\mathrm{pH}=7.4$, for $1,7,14,21$ and 28 days. PBS solution was refreshed every three days and after each timepoint ended, the samples were rinsed with PBS, and then dried and weighed. In order to evaluate the swelling rate of the prepared PVPA-ESM-rGO nanofibers wound dressings with different amount of rGO were soaked in PBS ( $\mathrm{pH}$ 7.4) solution for different times at ambient temperature. This procedure was continued until no more weight increasing was observed in the samples. The degree of swelling of these composite films at equilibrium was calculated based on following Equation [46]:

$$
\mathrm{Q}=\left(\mathrm{W}_{\mathrm{w}}-\mathrm{W}_{\mathrm{d}} / \mathrm{W}_{\mathrm{d}}\right) \times 100
$$

where $W_{w}$ and $W_{d}$ are the weights of swollen and dry samples, respectively, and $Q$ is degree of swelling.

Scanning electron microscopy (SEM, JEOL JSM-6380LA, JEOL (Europe) BV, Nieuw-Vennep, Amsterdam, The Netherlands) was used to study the PVPA-ESM/rGO nanofibers morphology. Furthermore, field emission scanning electron microscopy (FE-SEM, Helios Nanolab 660, an acceleration voltage of up to $30 \mathrm{kV}$ ) was carried out to investigate the rGO nanosheets surface morphology. To determine the size of the electrospun nanofibers, Image J software was used. The phase components were determined using an $\mathrm{X}$-ray diffractometer (XRD, Siemens D5000) with $\mathrm{Cu}-\mathrm{K} \alpha$ radiation $\left(45 \mathrm{kV}, 40 \mathrm{~mA}, 2 \theta\right.$ of $\left.5-80^{\circ}\right)$ with a scanning speed of $4^{\circ} / \mathrm{min}$. Attenuated total reflectance-Fourier transform infrared spectroscopy (ATR-FTIR, Bruker tensor) was performed over a range of 600 to $3700 \mathrm{~cm}^{-1}$ with a resolution of $2 \mathrm{~cm}^{-1}$ to verify the functional groups of the prepared nanofibers.

\subsection{Cell Culture}

To investigate the cell compatibility and cytotoxicity of the nanofiber's samples, cell culture tests were performed by the extraction method using the PC12 cell lines obtained from Pasteur Institute of Iran. The nanofiber samples were equalized for the experiments based on their weight. After sterilizing the nanofibers samples in ethanol for $2 \mathrm{~h}$, and after rinsing samples with PBS solution $(\mathrm{pH}=7.4)$, the samples were exposed to autoclave. At the end, the samples were immersed in $600 \mu \mathrm{L}$ of culture medium overnight. The PC12 cells with a cell density of $2 \times 10^{4}$ per culture dish were seeded on samples and kept at $37{ }^{\circ} \mathrm{C}$ under $5 \% \mathrm{CO}_{2}$ condition by refreshing the culture medium every three days. To evaluate samples' cytotoxicity, the colorimetric analysis was used. After 3 and 7 days of incubation, the culture medium was discarded. The samples were then rinsed with a PBS solution and then immersed in $2.5 \%$ glutaraldehyde solution and $0.1 \%$ osmium tetroxide 
for $3 \mathrm{~h}$ and $40 \mathrm{~min}$, respectively. The optical density was measured using an Elisa plate reader (STAT FAX 2100, Palm, FL, USA) at $545 \mathrm{~nm}$ wavelength. Finally, the mean and standard deviation of the cell viability of each sample were reported [23].

\subsection{Statistical Analysis}

The test results were reported as the mean \pm standard error (SE), and to show the significant difference among all data, GraphPad Prism software was used to analyze the data with the $p$-value $<0.05(*)$. Data were analyzed for statistically significant differences with 2-way ANOVA and the Turkey test.

\section{Results and Discussion}

\subsection{Eggshell Membrane Characterization}

According to Figure 2a,b which shows the SEM images of ESM, many nanofibers are arranged without forming a specific direction in its network. The FTIR spectra of the prepared ESM specimen (Figure 2c) showed the characteristic peaks of ESM. As seen, the collagen's functional groups (I, V, X type) can be observed [47,48]. The characteristic peaks were observed at two various areas: the first area is between 3750 and $2500 \mathrm{~cm}^{-1}$ and the second area is below $1700 \mathrm{~cm}^{-1}$ [49]. The most intense peak in the area with higher wavelengths was observed at $3287 \mathrm{~cm}^{-1}$, related to the stretching mode of $\mathrm{O}-\mathrm{H}$ and $\mathrm{N}-\mathrm{H}$ groups [36,47]. The peaks at 3060, 2932, and $2869 \mathrm{~cm}^{-1}$ are related to the asymmetric stretching vibrations of the $\mathrm{C}-\mathrm{H}$ and $\mathrm{CH}_{2}$ groups, which agree with previous studies. The peaks at $1643 \mathrm{~cm}^{-1}$ ( $\mathrm{C}=\mathrm{O}$ stretching), $1536 \mathrm{~cm}^{-1}$ (amide $\mathrm{N}-\mathrm{H}$ bending), $1451 \mathrm{~cm}^{-1}\left(\mathrm{CH}_{2}\right.$ scissoring), $1109 \mathrm{~cm}^{-1}$ (amine C-N stretching), and $661 \mathrm{~cm}^{-1} \mathrm{v}(\mathrm{C}-\mathrm{S})$ were observed in the lower wavelength region [48]. The amorphous structure of the material is observed by the XRD pattern of the ESM specimen (Figure 2d) in the broad peak at around $20.2^{\circ}[48]$ as the composition of the natural ESM specimen includes a lot of amines, amides, and carboxylic compounds, which are mostly amorphous. Figure 2e represents the XRD patterns of rGO nano sheets. The characteristic peak of rGO was observed at $23.2^{\circ}(002)$ as reported by Yasin et al. [45]. Furthermore, the FE-SEM image of rGO nanosheets was shown in Figure 2f; as can be observed from Figure 2f, the reduced graphene oxide has a layered structure, with thin and homogeneous graphene plates.

\subsection{Morphology of the PVP-ESM-rGO Nanofibers}

The morphologies of the electrospun PVPA-ESM nanofibers with various rGO percentages are shown in SEM images (Figure 3a-d). Smooth and uniform fibers with an average diameter of $687 \pm 17 \mathrm{~nm}$ were observed in PVPA-ESM (Figure 3a). However, incorporating rGO into PVPA-ESM composite caused the formation of rougher fibers with smaller diameter. In the samples containing $0.5,1$ and $2 \mathrm{wt} . \%$ rGO (Figure $3 \mathrm{~b}-\mathrm{d}$ ), the fibrous diameters decreased to $552 \pm 43 \mathrm{~nm}, 521 \pm 25 \mathrm{~nm}$, and $485 \pm 15 \mathrm{~nm}$, respectively. The quality and size of electrospun fibers were highly dependent on different parameters such as viscosity, polymer concentration, solution conductivity, nanosheets particles, and type of polymer [50,51]. Increasing the solution conductivity results in the generation of much more homogeneous fibers and reduces the fibers' diameter [48]. The polymer solution conductivity is highly enhanced by adding rGO with high electrical conductivity, increasing the electric charges, and reducing the polymer fibers diameter [52]. However, to prevent inflammatory cells from moving to the lumen and lessen the dissemination of the growth factors out of the guide lumen, the scaffolds' pore size cannot be more than a specific size [29,51]. A corresponding histogram analysis exhibited the extended range of nanofibers diameters based on collagen fibrils $(10-300 \mathrm{~nm})$ in native tissue, implying the fabricated nanofibers may assist the cell growth. To disseminate oxygen, nutrients, and neurotrophic factors and prohibit the penetration of fibrous tissues, the perfect scaffolds for nerve tissue engineering should have nano to micrometer pore size in the range of $50 \mathrm{~nm}$ to $5 \mu \mathrm{m}[13]$. 
Based on the XRD patterns of the PVPA-ESM/rGO nanofibers, only two characteristic peaks were observed in the range of $11^{\circ}$ to $25^{\circ}$ after the crosslinking process (Figure 4 ). The first peak at $11.9^{\circ}$ was attributed to the homogenous distribution of PVPA and ESM within the fibers. The second $\left(23.4^{\circ}\right)$ was related to graphene nanosheet characteristic peak [15]. According to the XRD patterns of pure PVPA and ESM, both were semicrystalline with a broad peak at $19.6^{\circ}$ and $28.6^{\circ}$, respectively [26]. Both peaks vanished after mixing, and just one peek at $19.6^{\circ}$ could be identified, which could be due to their homogeneous blending and the interactions.
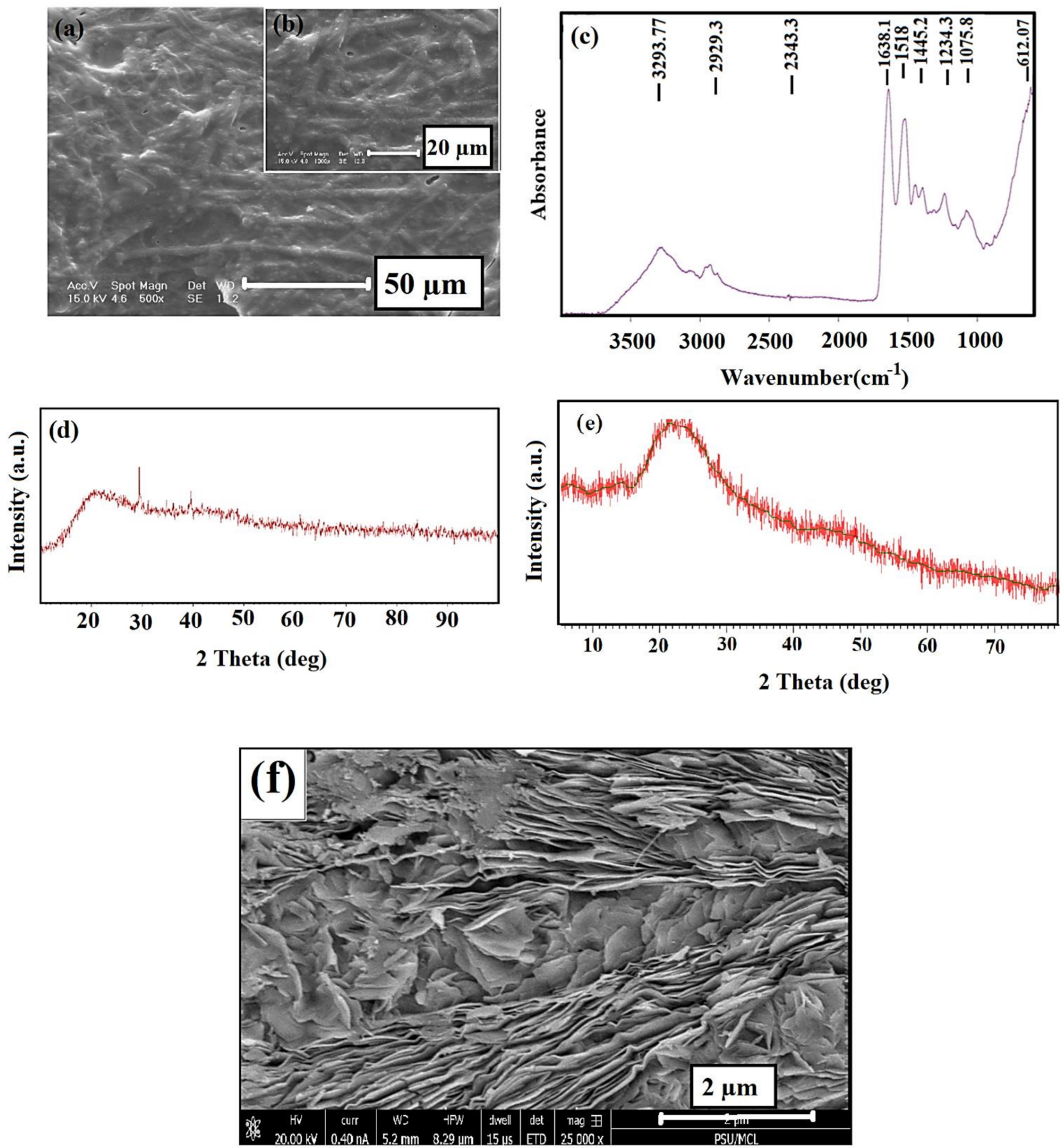

Figure 2. (a,b) SEM images, (c) FTIR spectra, (d) XRD pattern of eggshell membrane (ESM), (e) XRD pattern, and (f) FE-SEM images of rGO. 

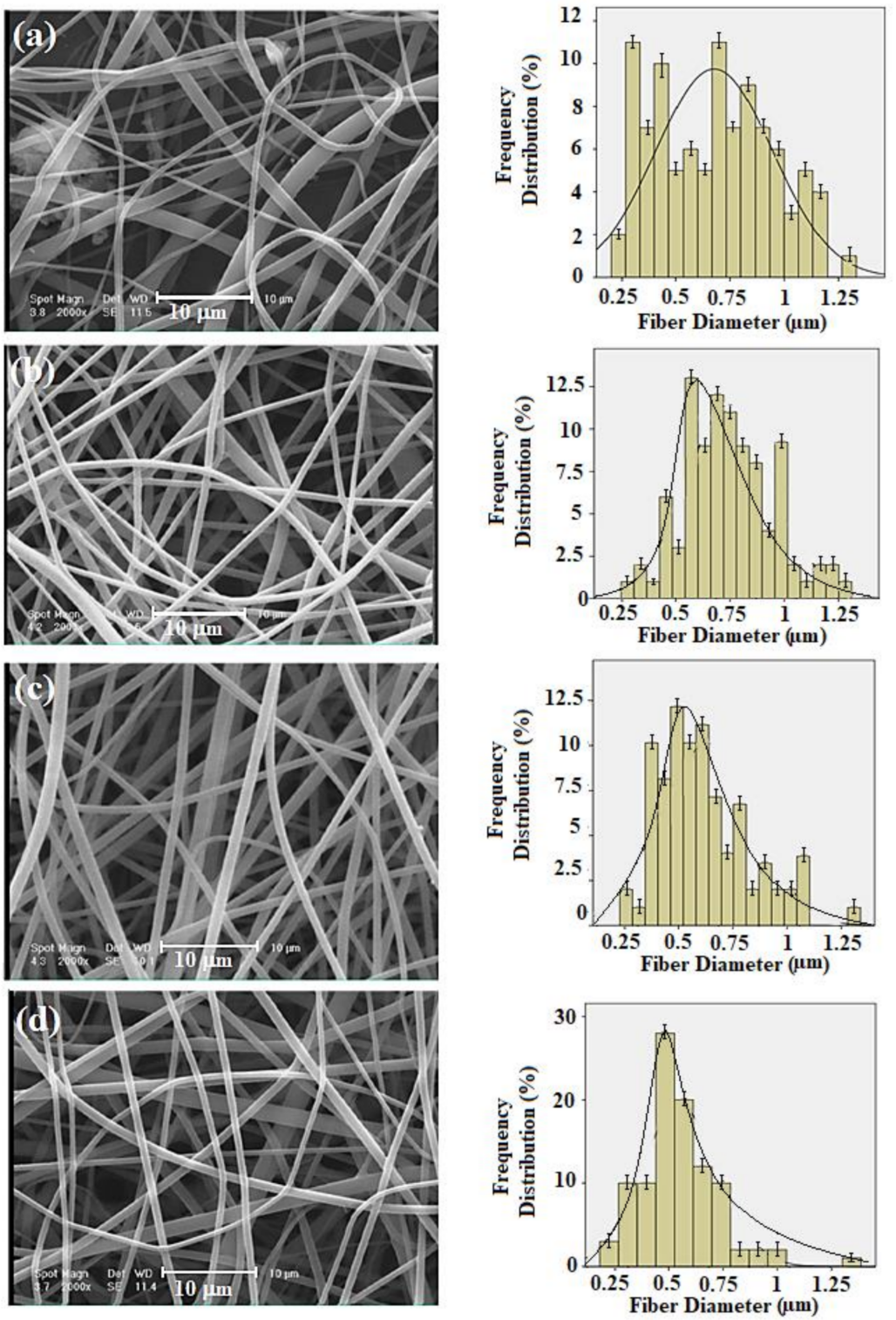

Figure 3. SEM images and frequency distribution of the fiber diameter for (a) PVPA-ESM, (b) PVPA-ESM $/ 0.5$ wt.\% rGO, (c) PVPA-ESM $/ 1$ wt.\% rGO, and (d) PVPA-ESM $/ 2$ wt.\% rGO fibers.

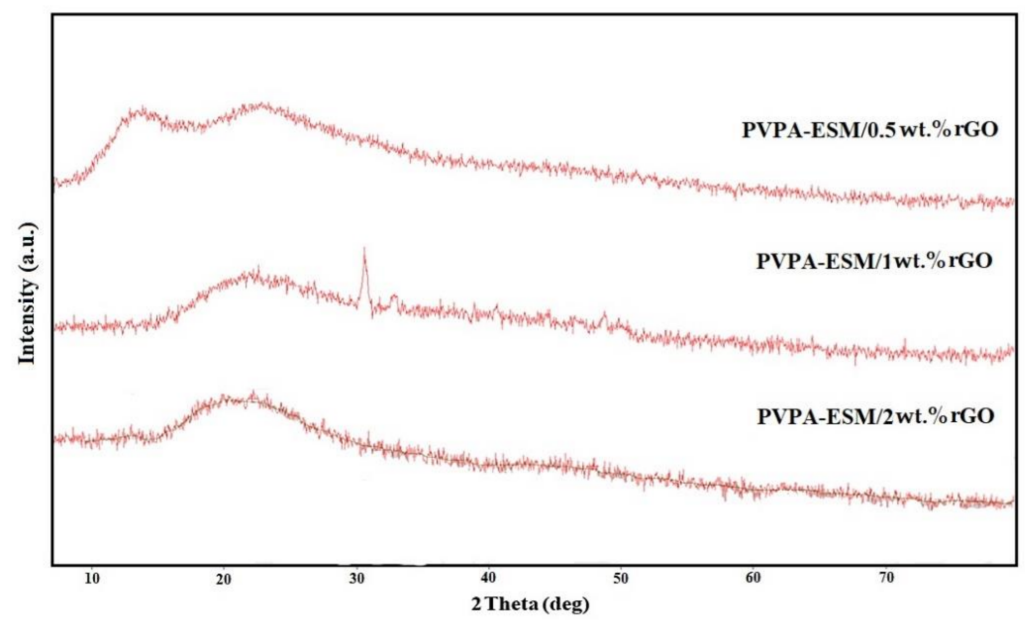

Figure 4. X-ray diffraction patterns of the electrospun PVPA-ESM/xwt. $\% \mathrm{rGO}$ nanofibers $(\mathrm{x}=0.5,1$ and $2 \mathrm{wt.} \%)$. 


\subsection{FTIR Analysis}

The FTIR spectrum of the PVPA, ESM, rGO, and PVPA-ESM/xwt.\%rGO nanofibers were demonstrated in Figure 5. FTIR spectrum of PVPA showed the characteristic peak at $2891 \mathrm{~cm}^{-1}$ for $\mathrm{CH}$ stretching [18]. The adsorption peaks at $1312 \mathrm{~cm}^{-1}$ and $1631 \mathrm{~cm}^{-1}$ show stretching vibrations in amide band III $(C-N)$ and carbonyl $(C=O)$, respectively. The characteristic peaks at $1290 \mathrm{~cm}^{-1}, 1660 \mathrm{~cm}^{-1}$, and $2921 \mathrm{~cm}^{-1}$ correspond to stretching vibrations in $\mathrm{C}-\mathrm{N}, \mathrm{C}=\mathrm{O}$, and $\mathrm{C}-\mathrm{H}$, respectively $[19,20]$. The FTIR spectrum of rGO exhibits characteristic peaks corresponding to the $\mathrm{O}-\mathrm{H}$ vibrations at $3412 \mathrm{~cm}^{-1}$. Furthermore, the characteristic stretching vibrations peaks of $C=O$ and $C=C$ were observed at $1726 \mathrm{~cm}^{-1}$ and $1620 \mathrm{~cm}^{-1}$. A more prominent peak at $1067 \mathrm{~cm}^{-1}$ correspond to the $\mathrm{C}-\mathrm{O}$ peak [45]. The FTIR spectrum of samples with various rGO concentrations confirmed that the rGO was incorporated into nanofibers (Figure 5). The characteristic peaks of PVPA-ESM polymer and rGO were observed in this Figure 5, which established the formation of bands between PVPA-ESM polymer composite and rGO nanosheet. The nanofibers indicated the characteristic peaks of PVPA at $1360 \mathrm{~cm}^{-1}$ and $1443 \mathrm{~cm}^{-1}$ related to $\mathrm{O}-\mathrm{H}$ and $\mathrm{C}-\mathrm{H}$ bonding. Furthermore, the PVPA polymer's distinct peaks showed the crystallinity of this polymer at $1143 \mathrm{~cm}^{-1}$ [6]. The other peaks in Figure 5 were related to ESM polymer. The FTIR spectrum of ESM included a lot of peaks at $3278 \mathrm{~cm}^{-1}$, which could be ascribed to the vibration of $\mathrm{O}-\mathrm{H}$ and $\mathrm{N}-\mathrm{H}$ groups. The peaks at 1631,1529 and $1236 \mathrm{~cm}^{-1}$ were related to a carbonyl group $(\mathrm{C}=\mathrm{O})$, amide II $(\mathrm{C}-\mathrm{N}$ and $\mathrm{N}-\mathrm{H})$, and amide III of the glycoprotein mantle of the ESM, respectively [26]. The characteristic peaks of rGO nanosheet were observed at around $1580 \mathrm{~cm}^{-1}$ (G-band) and $1340 \mathrm{~cm}^{-1}$ (D-band). However, the structural defects (disorder-induced modes) of the graphene samples caused that the $\mathrm{D}-$ and $\mathrm{rGO}-\mathrm{band}$ to be attributed to the graphitic carbons with sp2 hybridization [53]. The rGO's characteristic peaks were significantly decreased when dispersed in the PVPA-ESM matrix [6].

\subsection{Mechanical Properties}

The mechanical properties of wound dressings are one of the important factors due to their effects on the healing process. The evaluation of tensile strength and strain at break point is very important for initial and irradiated wound film of single-phase and composite components [54]. The tensile strength and strain of modified and unmodified samples are shown in Figure 6a,b. The composite nanofibers withstand high loads and sustain deformation when they are utilized to help the performance of tissue engineering scaffolds. The tensile strength of the nanofibers was increased by incorporation the different percentages of rGO up to $1 \%$. Furthermore, the same behavior was observed in the tensile strain at the failure point. The tensile strength and strain of PVPA-ESM/0.5 wt.\% rGO and PVPA-ESM/1 wt. $\%$ rGO were increased from $3.16 \pm 0.81 \mathrm{MPa}$ to $3.4 \pm 0.95 \mathrm{MPa}$ and $37.1 \pm 3.2$ to $43.2 \pm 4.12 \%$, respectively. By incorporating $2 \mathrm{wt} . \% \mathrm{rGO}$, tensile strength and strain reduced to $2.65 \pm 0.71 \mathrm{MPa}$ and $30.2 \pm 3.51 \mathrm{wt} . \%$, respectively. The tensile strength and deformation resistance of the PVPA-ESM nanofibers without rGO was $28 \%$ and $23 \%$ less than that of the sample with $0.5 \%$ rGO. Moreover, aggregation of rGO nanosheets in the PVPA-ESM/rGO composite structure occurred in the specimens with a high concentration of rGO (2 wt.\%). This is due to the rougher structure and the significant difference in the diameter of fibers in samples with a higher rGO concentration. Furthermore, the high degree of agglomeration of $\mathrm{rGO}$ in polymeric matrix and consequently the reduction of the interaction between rGO and PVPA-ESM is another reason for the reduction of mechanical properties. Gholafshan et al. [54] synthesized a nanohybrid interpenetrating network hydrogel composed of laponite:polyvinyl alcohol (PVA)-alginate by gel casting method for wound healing application. The tensile strength, elastic modulus, elongation, and toughness of optimized laponite:polyvinyl alcohol (PVA)-alginate with $0.5 \mathrm{wt} . \%$ laponite was found to be $0.45 \mathrm{MPa}, 1 \mathrm{MPa}, 140 \%$, and 0.35 , respectively, which are still far away from the mechanical properties of PVPA-ESM-rGO composite that we fabricated in this study. 


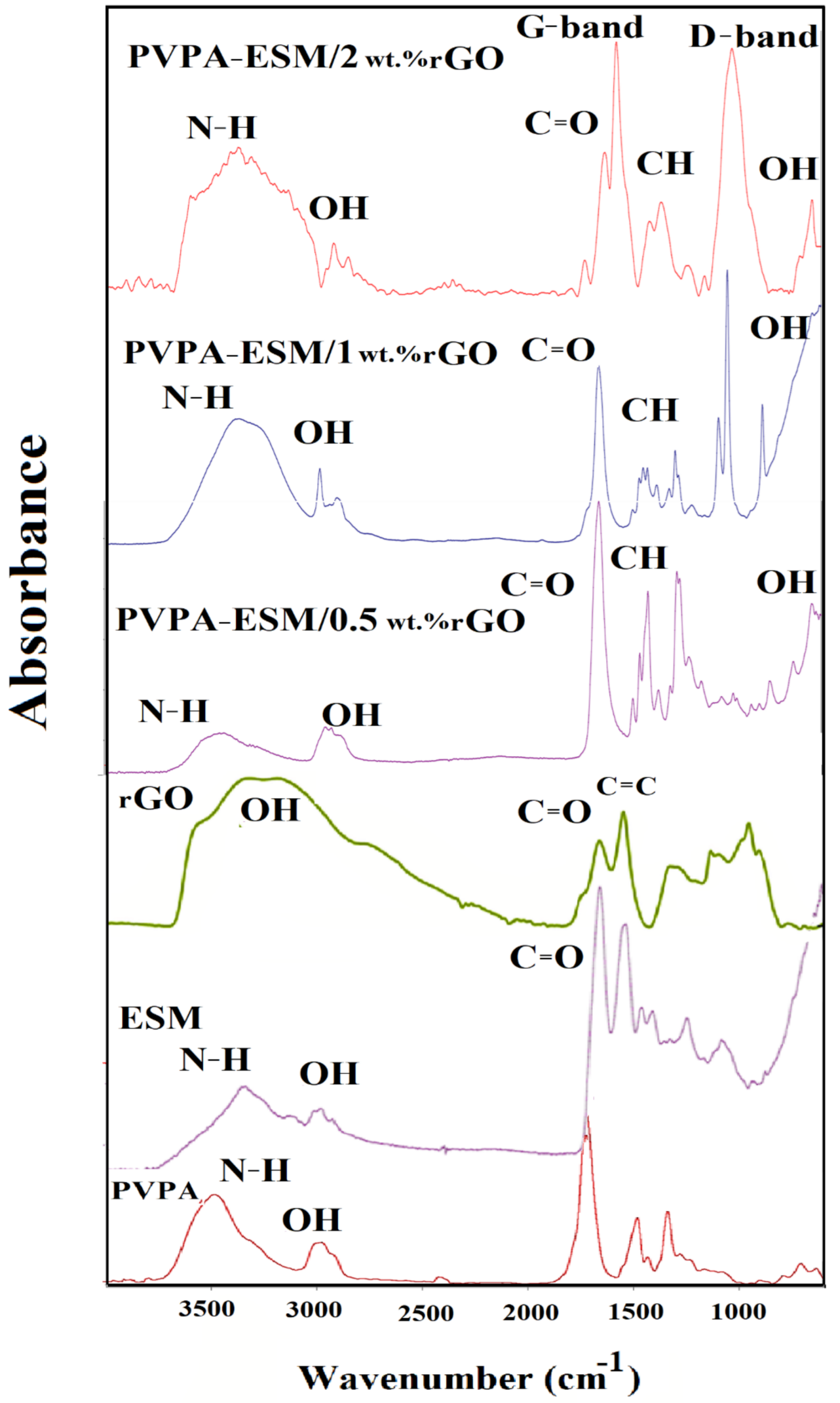

Figure 5. FTIR spectrum of the, PVPA, ESM, rGO, and PVPA-ESM/x wt.\% rGO nanofibers with various rGO concentrations ( $x=0,0.5,1$ and 2 wt. $\%$ ). 

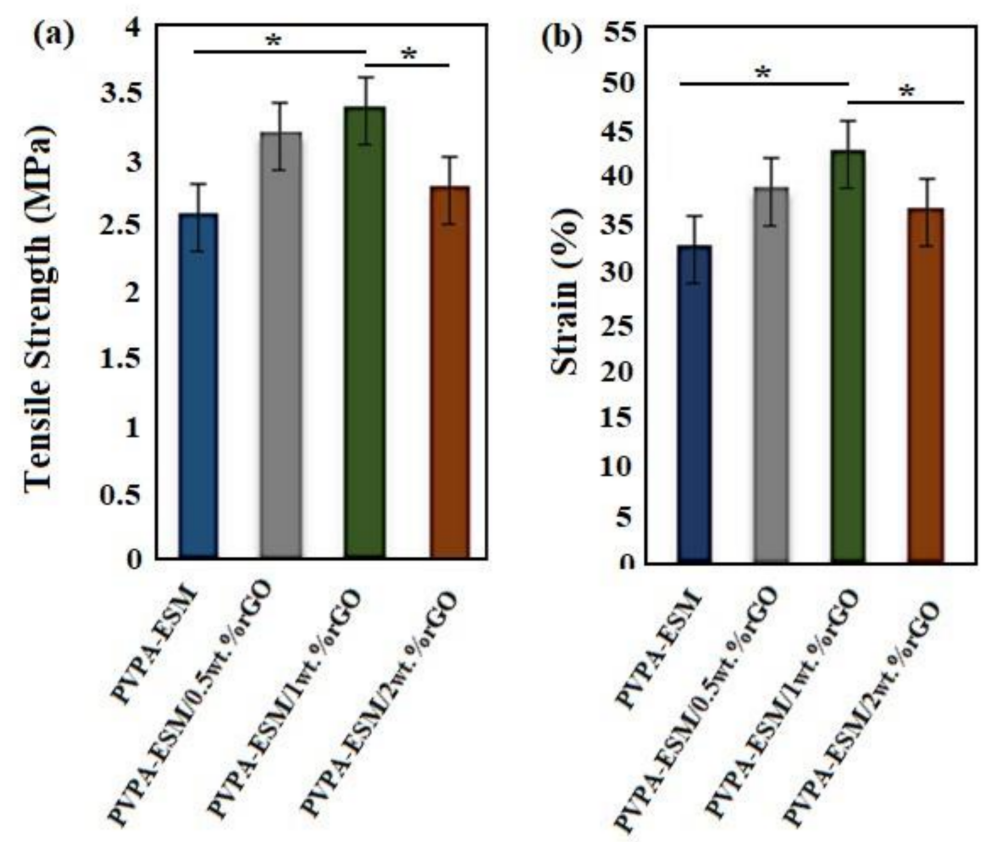

Figure 6. (a) Tensile strength, and (b) strain at break of PVPA-ESM/x wt.\% rGO nanofibers with various $\mathrm{rGO}$ concentrations $(\mathrm{x}=0,0.5,1$ and $2 \mathrm{wt} . \%)\left(p^{*}<0.05\right)$.

\subsection{Contact Angle, Degradation Behavior and Swelling Results}

The water contact angle of electrospun PVPA-ESM composite nanofibers was compared with modified samples with rGO (Figure 7). A spherical water droplet with a contact angle of $17.8^{\circ}$ was observed on the PVPA-ESM nanofibers surface. Increasing the amount of rGO to $0.5,1$ and $2 \mathrm{wt} . \%$ increased the water droplet's contact angle to $25.7^{\circ}, 33.8^{\circ}$ and $38.4^{\circ}$, respectively. When rGO was added, the nanofibers composite showed a hydrophobic nature. It was shown that pristine rGO has a contact angle of $58^{\circ}$ due to the oxygen-containing functional groups on their surface [53]. The PVPA-ESM-containing rGO showed an increased water contact angle. It was also reported in the literature that rGO nanosheets have had a useful role in the water impermeability of the nanofiber scaffolds [55]. These nanofibers will have a higher potential to be used in biomedical applications due to their excellent biocompatibility.

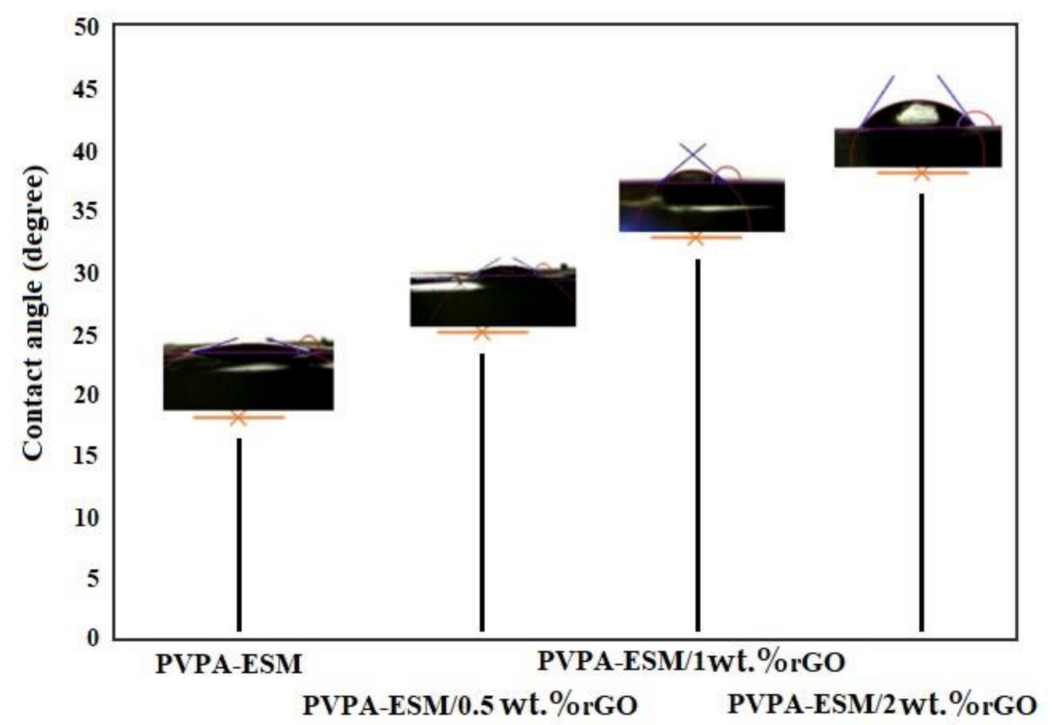

Figure 7. Contact angle measurements of the electro-spun PVPA-ESM/x wt.\% rGO nanofibers with various rGO concentrations ( $x=0,0.5,1$ and $2 \mathrm{wt} . \%)$. 
Mechanical properties of implants are influenced by their degradation in the body environment, which is one of the most crucial features of hydrophilic-based nanofibers. As seen in Figure 8, there is a difference between the degradation of PVPA-ESM/rGO nanofibers with various amounts of rGO and PVPA-ESM. After 28 days of soaking in PBS, the degradation rate was reduced from $30.8 \pm 2.6 \%$ (for PVPA-ESM-2 wt. $\%$ rGO) to $10.8 \pm 1.1 \%$ (for PVPA-ESM $/ 0.5$ wt. $\%$ rGO) and $10.1 \pm 1.1 \%$ (for PVPA-ESM). This could be due to the strong interaction between rGO and PVPA-ESM networks that can bridge the cleaved PVPA-ESM chains, causing a delay in nanofiber degradation. The composite of methacrylate rGO-gelatin methacryloyl (GelMA) hybrid hydrogel has shown the same behavior [56]. However, the degradation rate $(p<0.05)$ was significantly increased by increasing the rGO amount in the PVPA-ESM nanofibers. This is due to the interaction between rGO nanosheets and the PVPA-ESM polymer network. rGO agglomeration in samples enhanced the polymer degradation and the release of rGO. An ideal wound dressing for skin regeneration should absorb wound fluid to prevent infection of wound. A highly porous three-dimensional network of this composite has a positive effect on cell penetration and diffusion of nutrients, metabolites and other signaling molecules as well as allowing good vascularization due to its water uptake ability [57]. The degree of swelling of different wound dressing composite PVPA-ESM in various amount of rGO nanosheets was demonstrated in Figure 8b. As can be seen, the swelling rates of composites hydrogels were very fast at the initial stage. As shown in Figure $8 \mathrm{~b}$ the sample with $0,0.5$ and $2 \mathrm{wt} . \% \mathrm{rGO}$ showed the same swelling behavior and showed the lowest degree of swelling. Although the PVP is hydrophilic but does not have good absorption capacity, but when blended with rGO nano sheets, its swelling property increased significantly. It can be easily observed (Figure $8 b$ ) that all the composites went to an equilibrium condition after $300 \mathrm{~min}$ immersion in PBS. The maximum degree of swelling was observed for samples with $1 \%$ rGO nano sheets $1235 \%$ after $420 \mathrm{~min}$. This high swelling property of PVPA-ESM/1 wt.\% GO composite dressing can be explain by the presence of hydrophilic groups on the surface of rGO nanosheets. These functional groups fastened the water diffusion in the polymer networks. In contrast, increasing the rGO nanosheets to $2 \mathrm{wt} . \%$ reduced the swelling degree due to agglomeration of rGO nanosheets which decreased the interactions between rGO nanosheets and the polymer network. In a work done by Golaphshan et al. [54], they characterized the swelling ratio of polyvinyl alcohole-alginate-laponite. They reported that, after $24 \mathrm{~h}$ soaking, the swelling ratio of polyvinyl alcohole-alginate was measured as $274.6 \pm 6.5 \%$, while incorporating various amounts of laponite in this composite resulted in a decrease in the swelling ratio up to 3.2 times for composite with $2 \mathrm{wt} . \%$ laponite.

\subsection{In Vitro Study}

The hydrogel of biocompatible wound dressings should create a suitable microenvironment and could increase cell migration, hemostatic, and adhesion, and aid angiogenesis and connective tissue regeneration. Thus, another critical factor in selecting the right biomaterials for the fabrication of wound dressings is biocompatibility $[23,58]$. The cytotoxicity of PVPA-ESM nanofibers with various percentages of $\mathrm{rGO}(0,0.5,1$ and $2 \mathrm{wt} . \%)$ was performed using the MTT test. The cell viability of the control sample was $100 \%$. According to the results, the cell viability of PVPA-ESM nanofibers after 3 and 7 days was $65 \%$ and $71 \%$ [58], which indicated the toxicity of PVPA-ESM (Figure 9). The cell viability percentage of PC12 cultured of modified samples after 3 and 7 days are presented in Figure 9, too. In the PV-ESM $0.5 \mathrm{wt} . \%$ rGO and PV-ESM $1 \mathrm{wt} . \%$ rGO samples, the rate of cell viability was above $85 \%$ (after both 3 and 7 days), which indicated the nontoxic behavior of those samples. For the sample with 2 wt. $\%$ rGO, the cell viability percentage after 3 and 7 days was 73 and $74 \%$. A considerable reduction $(p<0.05)$ of cell viability was observed in the PVPA-ESM $/ 2$ wt. $\%$ rGO nanofibers based on the statistical analysis results. Based on the MTT assay, the toxicity of the PVPA-ESM sample was significantly reduced by the incorporation of $0.5 \mathrm{wt} . \% \mathrm{rGO}$ compared to other groups. As observed, various factors, including the type of nanosheets particles, $\mathrm{pH}$ changes in the culture medium, and the 
time of culture, affected the cell viability. The presence of rGO in the modified samples and the release of rGO in the medium were the main reason of increased cell viability. However, note that by increasing the release of rGO nanosheets in the culture medium, a reduction in cell viability was observed due to the toxicity effect of the agglomerate rGO with a high concentration and subsequent direct connection of $\mathrm{rGO}$, which resulted in cell destruction. However, the culture time extended from 3 to 7 days led to the enhanced cell viability exposed to PVPA-ESM/x rGO extracts. According to Golafshan et al. [6], the cytocompatibility and proliferation of PC12 cells can be improved by including nanofillers, especially carbon nanofiber, in comparison to the PCL scaffolds. In this regard, it was also reported [59] that because of the forceful attraction between nanomaterials and polymers, cell adhesion and proliferation increased by incorporating carbon-based nanomaterials into natural substrates [60]. In another study by Jeong et al. [61], the adhesion, growth, and morphology of cultured breast cancer cells on a silicon substrate-graphene oxides (rGO) - were investigated. Based on their results, it was observed that the spreading area and number of cells were highly dependent on the hydrophobicity and the presence of oxygenated groups on rGO and Si substrates, suggesting hydrophobicity-driven cell growth. Adding the rGO nanosheets results in controlling the adhesion and growth of cells on the surface of samples [61].

(a)

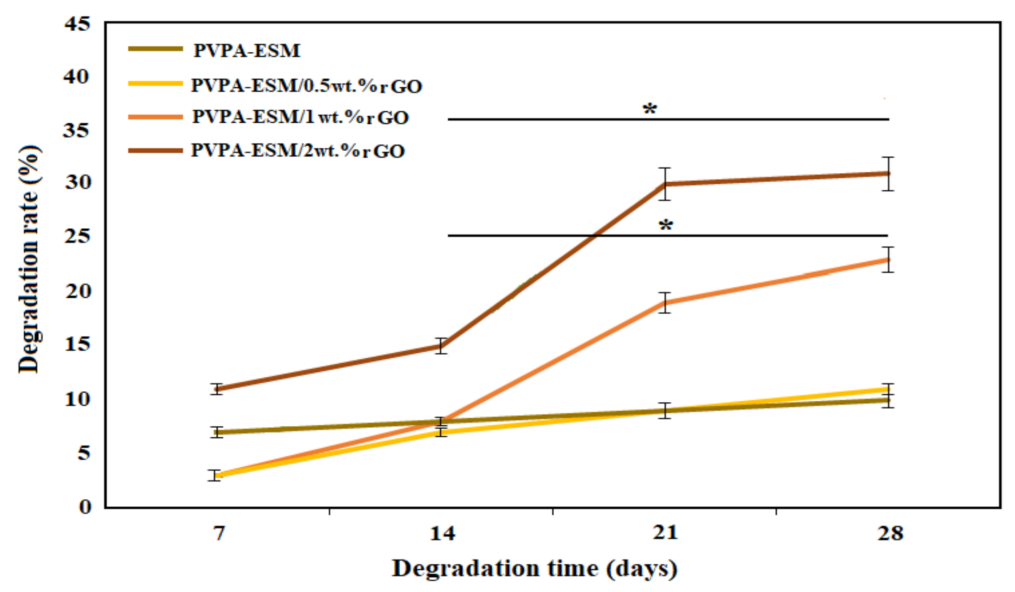

(b)

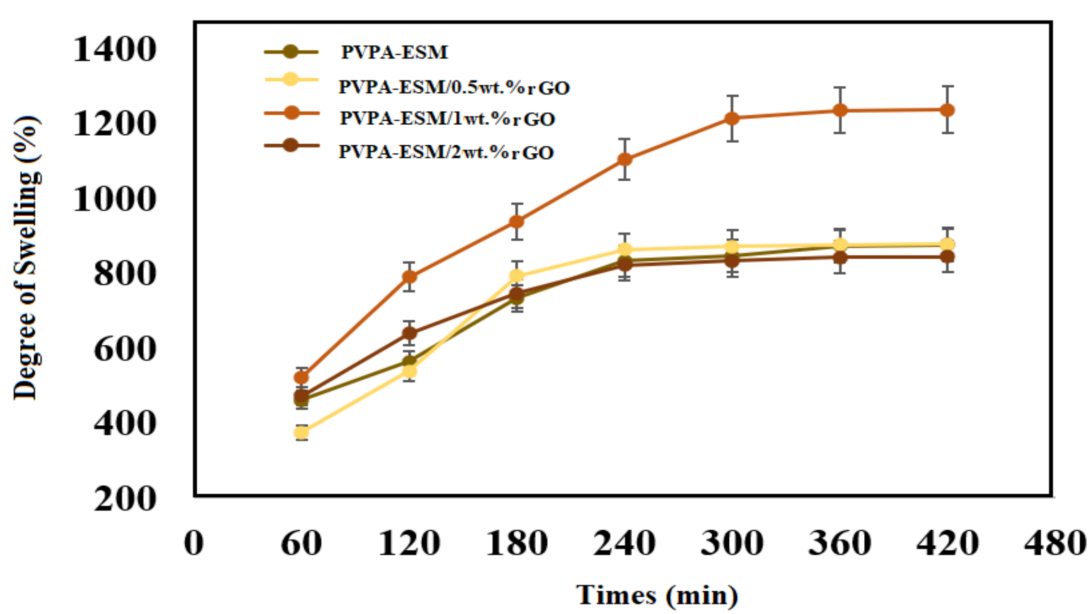

Figure 8. (a) Degradation rate and (b) degree of swelling of the electrospun PVPA-ESM and PVPA-ESM/x wt. $\%$ rGO nanofibers with various amount of rGO nanosheets ( $x=0,0.5,1$ and $2 \mathrm{wt} . \%)$ as a function of the soaking time $\left(p^{*}<0.05\right)$. 


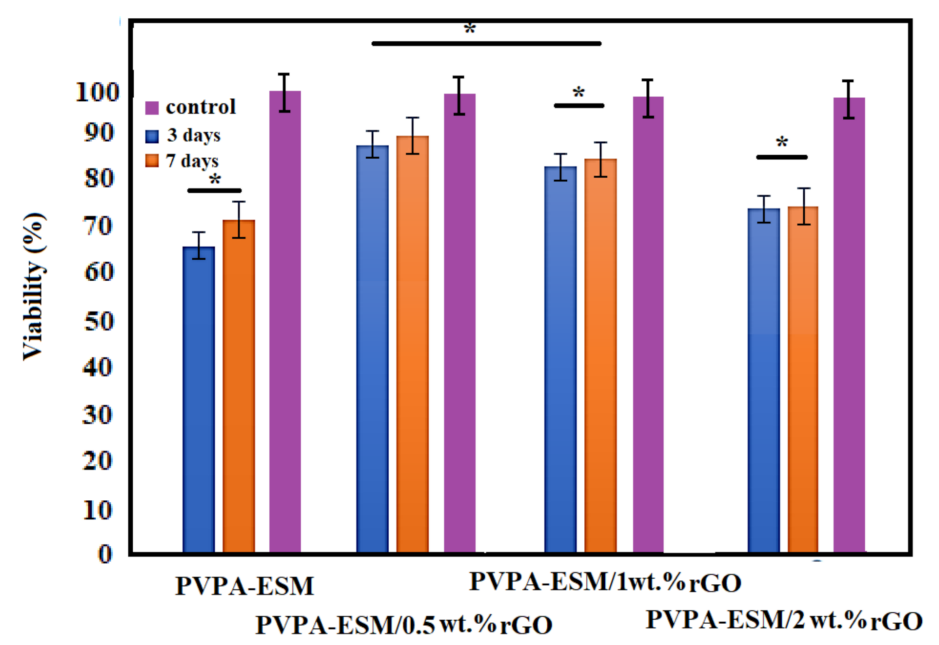

Figure 9. Cell viability of PVPA-ESM/x wt.\% rGO nanofibers with various rGO concentrations $(\mathrm{x}=0,0.5,1$ and $2 \mathrm{wt} . \%)$ ( ${ }^{*}$ not significantly difference between various samples, $\left.p>0.05\right)$.

\section{Conclusions}

To assist skin regeneration, graphene oxide (rGO)-loaded polyvinylpyrrolidone/eggshell membrane (PVPA-ESM) nanofibers were fabricated via electrospinning. The nanofibers had a porous and interconnected morphology featuring bead-free and randomly aligned continuous nanofibers. The rGO content increase enhanced the degradation behavior, mechanical strength, and deformation resistance, but mechanical features were reduced by adding 2 wt.\% rGO into the PVPA-ESM nanofibers. The results confirmed that the incorporation of $2 \mathrm{wt}$ \% rGO within the interpenetrating network of PVPA-ESM, respectively increased and reduced its degradation and swelling ratio. According to the MTT assay results, in the pristine PVPA-ESM and PVPA-ESM-rGO nanofibers with more rGO, cell survival was lower. These results showed that increasing the rGO content in the sample enhances the cytotoxicity.

Author Contributions: Investigation, S.G.S.; methodology, S.G.S.; project administration, R.E., M.A. and F.T.; supervision, R.E., M.A. and F.T.; writing-original draft, S.G.S. and S.S.; writing-review and editing, S.S., R.E., M.A. and F.T. All authors have read and agreed to the published version of the manuscript.

Funding: This research received no external funding.

Institutional Review Board Statement: Not applicable.

Informed Consent Statement: Not applicable.

Data Availability Statement: The raw/processed data required to reproduce these findings cannot be shared at this time as the data also forms part of an ongoing study. If you need to have access to some of the raw data, please contact the corresponding author.

Conflicts of Interest: The authors declare no conflict of interest.

\section{References}

1. Chrit, L.; Bastien, P.; Biatry, B.; Simonnet, J.; Potter, A.; Minondo, A.M.; Flament, F.; Bazin, R.; Sockalingum, G.D.; Leroy, F. In vitro and in vivo confocal Raman study of human skin hydration: Assessment of a new moisturizing agent, pMPC. Biopolym. Orig. Res. Biomol. 2007, 85, 359-369. [CrossRef]

2. Sarvari, R.; Sattari, S.; Massoumi, B.; Agbolaghi, S.; Beygi-Khosrowshahi, Y.; Kahaie-Khosrowshahi, A. Composite electrospun nanofibers of reduced graphene oxide grafted with poly (3-dodecylthiophene) and poly (3-thiophene ethanol) and blended with polycaprolactone. J. Biomater. Sci. Polym. Ed. 2017, 28, 1740-1761. [CrossRef] [PubMed]

3. Du, F.; Sun, L.; Huang, Z.; Chen, Z.; Xu, Z.; Ruan, G.; Zhao, C. Electrospun reduced graphene oxide/TiO2/poly (acrylonitrile-comaleic acid) composite nanofibers for efficient adsorption and photocatalytic removal of malachite green and leucomalachite green. Chemosphere 2020, 239, 124764. [CrossRef] [PubMed] 
4. Cao, L.; Zhang, F.; Wang, Q.; Wu, X. Fabrication of chitosan/graphene oxide polymer nanofiber and its biocompatibility for cartilage tissue engineering. Mater. Sci. Eng. C 2017, 79, 697-701. [CrossRef]

5. Parham, S.; Kharazi, A.Z.; Bakhsheshi-Rad, H.R.; Ghayour, H.; Ismail, A.F.; Nur, H.; Berto, F. Electrospun Nano-Fibers for Biomedical and Tissue Engineering Applications: A Comprehensive Review. Materials 2020, 13, 2153. [CrossRef] [PubMed]

6. Golafshan, N.; Kharaziha, M.; Fathi, M. Tough and conductive hybrid graphene-PVA: Alginate fibrous scaffolds for engineering neural construct. Carbon N. Y. 2017, 111, 752-763. [CrossRef]

7. Li, J.H.; Zhang, H.; Zhang, W.; Liu, W. Nanofiber membrane of graphene oxide/polyacrylonitrile with highly efficient antibacterial activity. J. Biomater. Sci. Polym. Ed. 2019, 30, 1620-1635. [CrossRef] [PubMed]

8. Yu, H.; Chen, X.; Cai, J.; Ye, D.; Wu, Y.; Liu, P. Dual controlled release nanomicelle-in-nanofiber system for long-term antibacterial medical dressings. J. Biomater. Sci. Polym. Ed. 2019, 30, 64-76. [CrossRef]

9. Li, T.; Liu, L.; Wang, L.; Ding, X. Solid drug particles encapsulated bead-on-string nanofibers: The control of bead number and its corresponding release profile. J. Biomater. Sci. Polym. Ed. 2019, 30, 1454-1469. [CrossRef]

10. Zhan, J.; Morsi, Y.; EI-Hamshary, H.; Al-Deyab, S.S.; Mo, X. Preparation and characterization of electrospun in-situ cross-linked gelatin-graphite oxide nanofibers. J. Biomater. Sci. Polym. Ed. 2016, 27, 385-402. [CrossRef]

11. Ardekani, N.T.; Khorram, M.; Zomorodian, K.; Yazdanpanah, S.; Veisi, H.; Veisi, H. Evaluation of electrospun poly (vinyl alcohol)based nanofiber mats incorporated with Zataria multiflora essential oil as potential wound dressing. Int. J. Biol. Macromol. 2019, 125, 743-750. [CrossRef]

12. Zha, Z.; Teng, W.; Markle, V.; Dai, Z.; Wu, X. Fabrication of gelatin nanofibrous scaffolds using ethanol/phosphate buffer saline as a benign solvent. Biopolymers 2012, 97, 1026-1036. [CrossRef]

13. Bakhsheshi-Rad, H.R.; Ismail, A.F.; Aziz, M.; Akbari, M.; Hadisi, Z.; Omidi, M.; Chen, X. Development of the PVA/CS nanofibers containing silk protein sericin as a wound dressing: In vitro and in vivo assessment. Int. J. Biol. Macromol. 2020, 149, 513-521. [CrossRef] [PubMed]

14. Li, W.; Cicek, N.; Levin, D.B.; Logsetty, S.; Liu, S. Bacteria-triggered release of a potent biocide from core-shell polyhydroxyalkanoate (PHA)-based nanofibers for wound dressing applications. J. Biomater. Sci. Polym. Ed. 2020, 31, 394-406. [CrossRef]

15. Yu, H.; Yang, P.; Jia, Y.; Zhang, Y.; Ye, Q.; Zeng, S. Regulation of biphasic drug release behavior by graphene oxide in polyvinyl pyrrolidone/poly ( $\varepsilon$-caprolactone) core/sheath nanofiber mats. Colloids Surf. B Biointerfaces 2016, 146, 63-69. [CrossRef] [PubMed]

16. Bhattacharjee, P.; Kundu, B.; Naskar, D.; Maiti, T.K.; Bhattacharya, D.; Kundu, S.C. Nanofibrous nonmulberry silk/PVA scaffold for osteoinduction and osseointegration. Biopolymers 2015, 103, 271-284. [CrossRef] [PubMed]

17. Hussain, T.; Ranjha, N.M.; Shahzad, Y. Swelling and controlled release of tramadol hydrochloride from a pH-sensitive hydrogel. Des. Monomers Polym. 2011, 14, 233-249. [CrossRef]

18. Naghdeali, M.H.; Miri, T.; Adimi, M.; Eskandari, H.; Nemati, N. Experimental investigation and modeling of release of antiasthmatic drug amino phylline from hydrogels based on PVP. Int. J. Biosci. 2014, 5, 275-280.

19. Maswal, M.; Chat, O.A.; Dar, A.A. Rheological characterization of multi-component hydrogel based on carboxymethyl cellulose: Insight into its encapsulation capacity and release kinetics towards ibuprofen. Colloid. Polym. Sci. 2015, 293, 1723-1735. [CrossRef]

20. Anwar, M.; Pervaiz, F.; Shoukat, H.; Noreen, S.; Shabbir, K.; Majeed, A.; Ijaz, S. Formulation and evaluation of interpenetrating network of xanthan gum and polyvinylpyrrolidone as a hydrophilic matrix for controlled drug delivery system. Polym. Bull. 2020, 7, 1-22. [CrossRef]

21. Muresan-Pop, M.; Magyari, K.; Vulpoi, A. PVA and PVP Hydrogel Blends for Wound dressing: Synthesis and characterisation. Adv. Mater. Res. 2019, 1151, 9-14. [CrossRef]

22. Sadeghzade, S.; Emadi, R.; Soleimani, B.; Tavangarian, F. Two-step modification process to improve mechanical properties and bioactivity of hydroxyfluorapatite scaffolds. Ceram. Int. 2018, 44, 19756-19763. [CrossRef]

23. Sadeghzade, S.; Emadi, R.; Tavangarian, F.; Doostmohammadi, A. In vitro evaluation of diopside/baghdadite bioceramic scaffolds modified by polycaprolactone fumarate polymer coating. Mater. Sci. Eng. C 2020, 106, 110176. [CrossRef]

24. Gil-Castell, O.; Galindo-Alfaro, D.; Sánchez-Ballester, S.; Teruel-Juanes, R.; Badia, J.D.; Ribes-Greus, A. Crosslinked sulfonated poly (vinyl alcohol)/graphene oxide electrospun nanofibers as polyelectrolytes. Nanomaterials 2019, 9, 397. [CrossRef] [PubMed]

25. Park, S.; Jeong, H.-K. Highly $\mathrm{H}_{2} \mathrm{O}$ Permeable Ionic Liquid Encapsulated Metal-Organic Framework Membranes for Energyefficient Air-Dehumidification. J. Mater. Chem. A 2020, 8, 23645-23653. [CrossRef]

26. Yang, C.; Yan, Z.; Lian, Y.; Wang, J.; Zhang, K. Graphene oxide coated shell-core structured chitosan/PLLA nanofibrous scaffolds for wound dressing. J. Biomater. Sci. Polym. Ed. 2020, 31, 622-641. [CrossRef]

27. Liang, J.; Yuan, C.; Li, H.; Fan, K.; Wei, Z.; Sun, H.; Ma, J. Growth of SnO 2 nanoflowers on N-doped carbon nanofibers as anode for Li-and Na-ion batteries. Nano-Micro Lett. 2018, 10, 21. [CrossRef] [PubMed]

28. Li, C.; Wang, X.; Chen, F.; Zhang, C.; Zhi, X.; Wang, K.; Cui, D. The antifungal activity of graphene oxide-silver nanocomposites. Biomaterials 2013, 34, 3882-3890. [CrossRef]

29. Wang, Y.; Lu, Y.; Gong, J.; Yao, Y. Electrospun nanofiber regulates assembly of keratin and vimentin intermediate filaments of PANC-1 pancreatic carcinoma cells. Mater. Sci. Eng. C 2019, 96, 616-624. [CrossRef] [PubMed]

30. Golafshan, N.; Kharaziha, M.; Fathi, M.; Larson, B.L.; Giatsidis, G.; Masoumi, N. Anisotropic architecture and electrical stimulation enhance neuron cell behaviour on a tough graphene embedded PVA: Alginate fibrous scaffold. RSC Adv. 2018, 8, 6381-6389. [CrossRef] 
31. Bakhsheshi-Rad, H.R.; Ismail, A.F.; Aziz, M.; Akbari, M.; Hadisi, Z.; Khoshnava, S.M.; Pagan, E.; Chen, X. Co-incorporation of graphene oxide/silver nanoparticle into poly-L-lactic acid fibrous: A route toward the development of cytocompatible and antibacterial coating layer on magnesium implants. Mater. Sci. Eng. C 2020, 111, 110812. [CrossRef]

32. Pant, H.R.; Park, C.H.; Tijing, L.D.; Amarjargal, A.; Lee, D.-H.; Kim, C.S. Bimodal fiber diameter distributed graphene oxide/nylon6 composite nanofibrous mats via electrospinning. Colloids Surf. A Physicochem. Eng. Asp. 2012, 407, 121-125. [CrossRef]

33. Yang, Z.; Sun, C.; Wang, L.; Chen, H.; He, J.; Chen, Y. Novel Poly (l-lactide)/graphene oxide films with improved mechanical flexibility and antibacterial activity. J. Colloid Interface Sci. 2017, 507, 344-352. [CrossRef]

34. Bharathi, B.S.; Stalin, T. Cerium oxide and peppermint oil loaded polyethylene oxide/graphene oxide electrospun nanofibrous mats as antibacterial wound dressings. Mater. Today Commun. 2019, 21, 100664. [CrossRef]

35. Liu, Y.; Park, M.; Shin, H.K.; Pant, B.; Choi, J.; Park, Y.W.; Lee, J.Y.; Park, S.-J.; Kim, H.-Y. Facile preparation and characterization of poly (vinyl alcohol)/chitosan/graphene oxide biocomposite nanofibers. J. Ind. Eng. Chem. 2014, 20, 4415-4420. [CrossRef]

36. Chen, X.; Zhu, L.; Wen, W.; Lu, L.; Luo, B.; Zhou, C. Biomimetic mineralisation of eggshell membrane featuring natural nanofiber network structure for improving its osteogenic activity. Colloids Surf. B Biointerfaces 2019, 179, 299-308. [CrossRef]

37. Saeb, M.R.; Ghaffari, M.; Rastin, H.; Khonakdar, H.A.; Simon, F.; Najafi, F.; Goodarzi, V.; Puglia, D.; Asl, F.H.; Formela, K. Biowaste chicken eggshell powder as a potential cure modifier for epoxy/anhydride systems: Competitiveness with terpolymer-modified calcium carbonate at low loading levels. RSC Adv. 2017, 7, 2218-2230. [CrossRef]

38. Abdulrahman, I.; Tijani, H.I.; Mohammed, B.A.; Saidu, H.; Yusuf, H.; Jibrin, M.N.; Mohammed, S. From garbage to biomaterials: An overview on egg shell based hydroxyapatite. J. Mater. 2014, 2014, 802467. [CrossRef]

39. Saeb, M.R.; Rastin, H.; Nonahal, M.; Paran, S.M.R.; Khonakdar, H.A.; Puglia, D. Cure kinetics of epoxy/chicken eggshell biowaste composites: Isothermal calorimetric and chemorheological analyses. Prog. Org. Coat. 2018, 114, 208-215. [CrossRef]

40. Bhagavatheswaran, E.S.; Das, A.; Rastin, H.; Saeidi, H.; Jafari, S.H.; Vahabi, H.; Najafi, F.; Khonakdar, H.A.; Formela, K.; Jouyandeh, M.; et al. The taste of waste: The edge of eggshell over calcium carbonate in acrylonitrile butadiene rubber. J. Polym. Environ. 2019, 27, 2478-2489. [CrossRef]

41. Ishak, N.; Chan, M.; Ang, S.C.; Cheung, C.; Teoh, S.H. Bioengineered three-dimensional transparent eggshell as a chicken embryo experimentation platform for biomedical research. Eng. Rep. 2020, 2, 12092. [CrossRef]

42. Kulshreshtha, G.; Ahmed, T.A.; Wu, L.; Diep, T.; Hincke, M.T. A novel eco-friendly green approach to produce particalized eggshell membrane (PEM) for skin health applications. Biomater. Sci. 2020, 8, 5346-5361. [CrossRef]

43. Baláž, M. Eggshell membrane biomaterial as a platform for applications in materials science. Acta Biomater. 2014, 10, 3827-3843. [CrossRef]

44. Yan, S.; Napiwocki, B.; Xu, Y.; Zhang, J.; Zhang, X.; Wang, X.; Crone, W.C.; Li, Q.; Turng, L.-S. Wavy small-diameter vascular graft made of eggshell membrane and thermoplastic polyurethane. Mater. Sci. Eng. C 2020, 107, 110311. [CrossRef] [PubMed]

45. Yasin, G.; Arif, M.; Shakeel, M.; Dun, Y.; Zuo, Y.; Khan, W.Q.; Tang, Y.; Khan, A.; Nadeem, M. Exploring the Nickel-Graphene Nanocomposite Coatings for Superior Corrosion Resistance: Manipulating the Effect of Deposition Current Density on its Morphology, Mechanical Properties, and Erosion-Corrosion Performance. Adv. Eng. Mater. 2018, 20, 1701166. [CrossRef]

46. Huang, Y.; Zeng, M.; Ren, J.; Wang, J.; Fan, L.; Xu, Q. Preparation and swelling properties of graphene oxide/poly (acrylic acid-co-acrylamide) super-absorbent hydrogel nanocomposites. Colloids Surf. A 2012, 401, 97-106. [CrossRef]

47. Choi, J.; Pant, B.; Lee, C.; Park, M.; Park, S.-J.; Kim, H.-Y. Preparation and characterization of eggshell membrane/PVA hydrogel via electron beam irradiation technique. J. Ind. Eng. Chem. 2017, 47, 41-45. [CrossRef]

48. Kang, J.; Kotaki, M.; Okubayashi, S.; Sukigara, S. Fabrication of electrospun eggshell membrane nanofibers by treatment with catechin. J. Appl. Polym. Sci. 2010, 117, 2042-2049. [CrossRef]

49. Da Silva, R.J.; Lima, R.M.A.P.; de Oliveira, M.C.A.; Alcaraz-Espinoza, J.J.; de Melo, C.P.; de Oliveira, H.P. Supercapacitors based on (carbon nanostructure)/PEDOT/(eggshell membrane) electrodes. J. Electroanal. Chem. 2020, 856, 113658. [CrossRef]

50. Sadeghzade, S.; Emadi, R.; Tavangarian, F.; Naderi, M. Fabrication and evaluation of silica-based ceramic scaffolds for hard tissue engineering applications. Mater. Sci. Eng. C 2017, 71, 431-438. [CrossRef]

51. Soleymani, F.; Emadi, R.; Sadeghzade, S.; Tavangarian, F. Applying Baghdadite/PCL/Chitosan Nanocomposite Coating on AZ91 Magnesium Alloy to Improve Corrosion Behavior, Bioactivity, and Biodegradability. Coatings 2019, 9, 789. [CrossRef]

52. Bakhsheshi-Rad, H.R.; Ismail, A.F.; Aziz, M.; Akbari, M.; Hadisi, Z.; Daroonparvar, M.; Chen, X.B. Antibacterial activity and in vivo wound healing evaluation of polycaprolactone-gelatin methacryloyl-cephalexin electrospun nanofibrous. Mater. Lett. 2019, 256, 126618. [CrossRef]

53. Torres, D.; Pérez-Rodríguez, S.; Sebastián, D.; Pinilla, J.L.; Lázaro, M.J.; Suelves, I. Graphene oxide nanofibers: A nanocarbon material with tuneable electrochemical properties. Appl. Surf. Sci. 2020, 509, 144774. [CrossRef]

54. Golafshan, N.; Rezahasani, R.; Esfahani, M.T.; Kharaziha, M.; Khorasani, S.N. Nanohybrid hydrogels of laponite: PVA-Alginate as a potential wound healing material. Carbohydr. Polym. 2017, 176, 392-401. [CrossRef]

55. Shuai, C.; Guo, W.; Wu, P.; Yang, W.; Hu, S.; Xia, Y.; Feng, P. A graphene oxide-Ag co-dispersing nanosystem: Dual synergistic effects on antibacterial activities and mechanical properties of polymer scaffolds. Chem. Eng. J. 2018, 347, 322-333. [CrossRef]

56. Zhao, R.; Kong, W.; Sun, M.; Yang, Y.; Liu, W.; Lv, M.; Song, S.; Wang, L.; Song, H.; Hao, R. Highly stable graphene-based nanocomposite (GO-PEI-Ag) with broad-spectrum, long-term antimicrobial activity and antibiofilm effects. ACS Appl. Mater. Interfaces 2018, 10, 17617-17629. [CrossRef] 
57. Roy, N.; Saha, N.; Kitano, T.; Saha, P. Novel hydrogels of PVP-CMC and their swelling effect on viscoelastic properties. J. Appl. Polym. Sci. 2010, 117, 1703-1710. [CrossRef]

58. Sadeghzade, S.; Emadi, R.; Tavangarian, F.; Doostmohammadi, A. The influence of polycaporolacton fumarate coating on mechanical properties and in vitro behavior of porous diopside-hardystonite nano-composite scaffold. J. Mech. Behav. Biomed. Mater. 2020, 101, 103445. [CrossRef] [PubMed]

59. Cheng, Y.; Peng, J.; Xu, H.; Cheng, Q. Glycera-Inspired Synergistic Interfacial Interactions for Constructing Ultrastrong GrapheneBased Nanocomposites. Adv. Funct. Mater. 2018, 28, 1800924. [CrossRef]

60. Ling, L.; Du, Y.; Ismail, M.; He, R.; Hou, Y.; Fu, Z.; Zhang, Y.; Yao, C.; Li, X. Self-assembled liposomes of dual paclitaxelphospholipid prodrug for anticancer therapy. Int. J. Pharm. 2017, 526, 11-22. [CrossRef] [PubMed]

61. Jeong, J.-T.; Choi, M.-K.; Sim, Y.; Lim, J.-T.; Kim, G.-S.; Seong, M.-J.; Hyung, J.-H.; Kim, K.S.; Umar, A.; Lee, S.-K. Effect of graphene oxide ratio on the cell adhesion and growth behavior on a graphene oxide-coated silicon substrate. Sci. Rep. 2016, 6, 1-10. [CrossRef] [PubMed] 